\title{
Investigation of the breakdown voltage in high voltage 4H-SiC BJT with respect to oxide and interface charges
}

\author{
Arash Salemi $^{1, a}$, Hossein Elahipanah ${ }^{1, b}$, Carl-Mikael Zetterling ${ }^{1, c}$ \\ and Mikael Östling ${ }^{1, d}$ \\ ${ }^{1} \mathrm{KTH}$ Royal Institute of Technology, 16440 Kista, Sweden \\ asalemi@kth.se, bhosseine@kth.se, cbellman@kth.se, ${ }^{\mathrm{a}}$ ostling@kth.se
}

Keywords: Bipolar junction transistor (BJT), silicon carbide (SiC), Junction termination extension (JTE), oxide, interface traps, fixed charges, implantation free

\begin{abstract}
Ion implantation in silicon carbide (SiC) induces defects during the process. Implantation free processing can eliminate these problems. The junction termination extension (JTE) can also be formed without ion implantation in $\mathrm{SiC}$ bipolar junction transistor (BJT) using a well-controlled etching into the epitaxial base layer. The fixed charges at the $\mathrm{SiC} / \mathrm{SiO}_{2}$ interface modify the effective dose of the JTEs, leakage current, and breakdown voltage. In this paper the influence of fixed charges (positive and negative) and also interface trap density at the $\mathrm{SiC} / \mathrm{SiO}_{2}$ interface on the breakdown voltage in $4.5 \mathrm{kV} 4 \mathrm{H}-\mathrm{SiC}$ non-ion implanted $\mathrm{BJT}$ have been simulated. $\mathrm{SiO}_{2}$ as a surface passivation layer including interface traps and fixed charges has been considered in the analysis. Simulation result shows that the fixed charges influence the breakdown voltage significantly more than the interface traps. It also shows that the positive fixed charges reduce the breakdown voltage more than the negative fixed charges. The combination of interface traps and fixed charges must be considered when optimizing the breakdown voltage.
\end{abstract}

\section{Introduction}

Owing to its superior properties of high breakdown electric field and high thermal conductivity, silicon carbide $(\mathrm{SiC})$ is one of the most attractive semiconductors for high-power, high-temperature, and high-frequency applications. Bipolar junction transistors (BJTs) are now reaching the market $[1,2]$. An applicable junction termination extension (JTE) is critical to avoid a significant reduction in the breakdown voltage in power devices due to electric field crowding at the edges. Ion implantation followed by high temperature annealing is applying to form the JTEs, but it makes crystalline damage and surface roughness and reduces the lifetime in SiC. Using etched junction termination extension (JTE) is a good candidate to avoid these problems [3,4]. $\mathrm{SiO}_{2}$ is an attractive material for passivation and gate dielectric. In the presence of the passivation layer, the equipotential contours spread out near the end of the JTEs. It alleviates the electric field and increases the breakdown voltage [5]. However, the interface trap density at the $\mathrm{SiC} / \mathrm{SiO}_{2}$ interface is about two orders of magnitude higher than for the $\mathrm{Si} / \mathrm{SiO}_{2}$ interface which affects the reliability and performance of the $\mathrm{SiC}$ power devices [6-8]. In recent years, there has been important progress to improve the current gain by focusing on improved surface passivation. It has been reported that the deposited oxides followed by high temperature annealing in $\mathrm{N}_{2} \mathrm{O}$ or NO show lower interface trap density than the thermally grown oxides [6,9-12]. In this work, the effect of fixed charges (positive and negative) and also the interface trap density at the $\mathrm{SiC} / \mathrm{SiO}_{2}$ interface on the breakdown voltage have been studied. The Sentaurus TCAD simulator has been carefully calibrated with our previous results and a good agreement is achieved [13,14].

\section{Device Structure and Simulation}

Fig. 1 shows a schematic cross-sectional view of the fabricated $4.5 \mathrm{kV}$ non ion-implanted $4 \mathrm{H}-\mathrm{SiC}$ BJT with optimized lengths and doses of JTEs [13]. Due to the process variation, a breakdown 
voltage more than $6 \mathrm{kV}$ was designed. The $\mathrm{n}^{+}$epilayer was $2 \mu \mathrm{m}$ thick, doped with nitrogen at $1 \times 10^{19} \mathrm{~cm}^{-3}$, and capped with a $200 \mathrm{~nm}$-thick $3 \times 10^{19} \mathrm{~cm}^{-3}$-doped layer. The base layer was $700 \mathrm{~nm}$ thick and doped with aluminum at $2.5 \times 10^{17} \mathrm{~cm}^{-3}$. The drift $\mathrm{n}^{-}$layer was $45 \mu \mathrm{m}$ thick and doped at $1.7 \times 10^{15} \mathrm{~cm}^{-3}$. The buffer layer was $4 \mu \mathrm{m}$ thick and doped with nitrogen at $1 \times 10^{16} \mathrm{~cm}^{-3}$. Since this work focuses on the open emitter breakdown $\left(\mathrm{BV}_{\mathrm{CBO}}\right)$, the simulation study of the breakdown voltage includes only the base-collector junction. Three-zone etched JTE with optimized lengths $(100,75,25 \mu \mathrm{m})$ have been applied in this study. The simulation results show the optimum remaining dose of $1.1 \times 10^{13} \mathrm{~cm}^{-2}, 1.0 \times 10^{13} \mathrm{~cm}^{-2}$, and $0.6 \times 10^{13} \mathrm{~cm}^{-2}$ for the JTE1, JTE2 and JTE3 for a stable breakdown voltage over $6 \mathrm{kV}$, respectively.

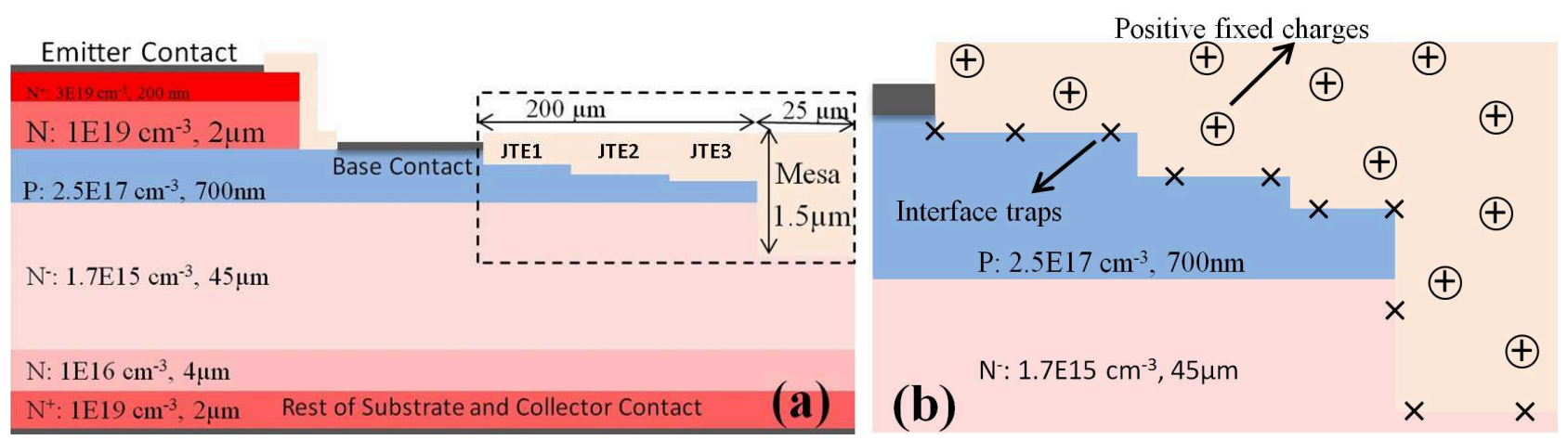

Fig. 1. Schematic cross-sectional view of the fabricated (a) non ion-implanted 4H-SiC BJT and (b) the position of the implemented fixed charges and the interface traps in the JTE zones.

\section{Results and Discussion}

In the absence of the fixed charges in the oxide or traps at the $\mathrm{SiC} / \mathrm{SiO}_{2}$ interface the electric field distribution is spreading through the full JTE area which eliminates the field crowding in the corners (Fig. 2a). The fixed charges change the electric field distribution, the leakage current and the breakdown voltage. They modify the effective dose of the JTEs, and change the location of the maximum electric field towards the base edge (Fig. 2b). Fig. 2c shows how the breakdown voltage decreases in the presence of the fixed charges.
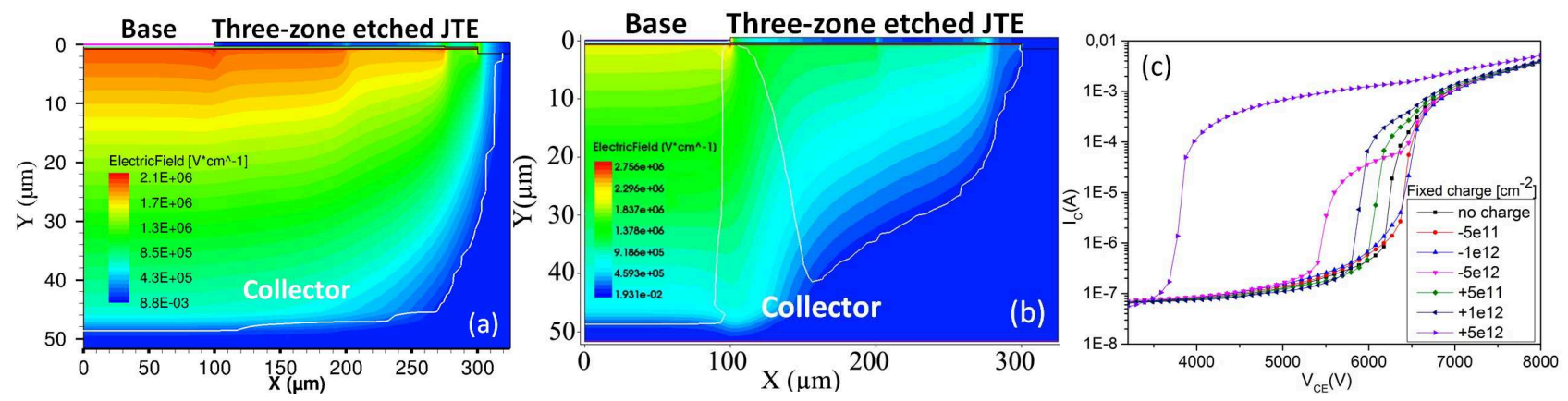

Fig. 2. Electric field distribution along the $4 \mathrm{H}-\mathrm{SiC}$ BJT (a) with optimized parameters, (b) in the presence of fixed charges $\left(+5 \mathrm{E} 12 \mathrm{~cm}^{-2}\right)$, (c) simulated I-V characteristics of the $4 \mathrm{H}-\mathrm{SiC} \mathrm{BJT}$ in the presence of different fixed charges.

The simulation results also show that the influence of the positive oxide charges on the electric field distribution is higher than the negative oxide charges. Therefore the positive fixed charges reduce the breakdown voltage more than the negative fixed charges. As can be seen from Fig. 3a, for the fixed charge concentration of $+5 \times 10^{12} \mathrm{~cm}^{-2}$ and $-5 \times 10^{12} \mathrm{~cm}^{-2}$ the breakdown voltage variation $\left(\Delta \mathrm{V}_{\mathrm{BR}}\right)$ of $-2430 \mathrm{~V}$ and $-750 \mathrm{~V}$ are obtained, respectively. Fig. $3 \mathrm{~b}$ shows the effect of the interface traps concentration on the breakdown voltage. The maximum $\Delta \mathrm{V}_{\mathrm{BR}}$ of $-288 \mathrm{~V}$ is obtained for the 
device with the trap concentration of $10^{14} \mathrm{~cm}^{-2}$. Comparing Fig. 3a and $3 \mathrm{~b}$ confirms that the fixed charges influence the breakdown voltage significantly more than the interface traps.
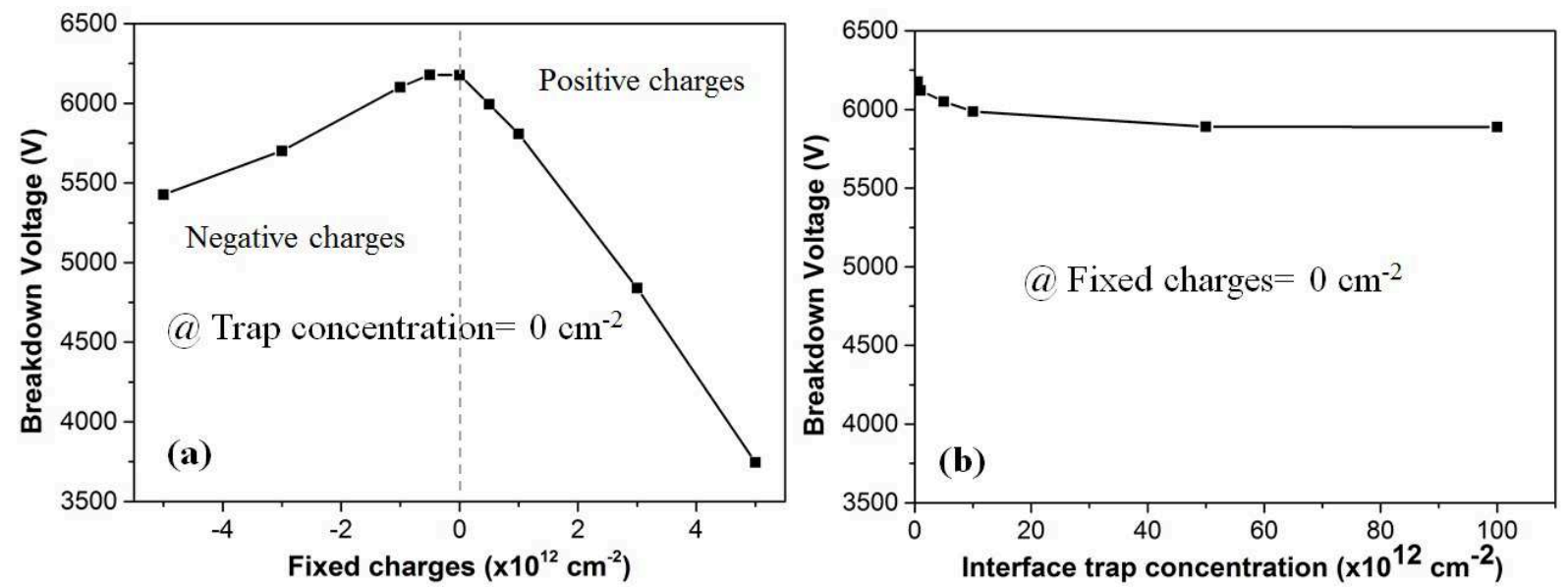

Fig. 3. Simulated breakdown voltage as a function of (a) positive and negative fixed charges and (b) interface trap concentration.

Moreover, the simulation results show that a higher $\mathrm{V}_{\mathrm{BR}}$ is achieved both interface traps and fixed charges are present in the JTE zones (Table I). For the positive charges, the breakdown voltage improves around $30 \%$ and the $\Delta V_{\mathrm{BR}}$ reaches to about $600 \mathrm{~V}$ with a trap concentration of $10^{14} \mathrm{~cm}^{-2}$; while the $\Delta V_{B R}$ is around $9 \%$ for the negative charges. It is also seen that a higher interface trap density decreases the $\Delta \mathrm{V}_{\mathrm{BR}}$ for positive fixed charges, while it acts reversely for negative fixed charges.

Table I. Breakdown voltage variation due to fixed charges and interface traps.

\begin{tabular}{|c|c|c|}
\hline Fixed charge $\left(\mathrm{cm}^{-2}\right)$ & Trap concentration $\left(\mathrm{cm}^{-2}\right)$ & $\Delta \mathrm{V}_{\text {BR }}(\mathrm{V})$ \\
\hline \multirow{3}{*}{$5 \mathrm{e} 12$} & $1 \mathrm{e} 13$ & -2040 \\
\cline { 2 - 3 } & $5 \mathrm{e} 13$ & -930 \\
\cline { 2 - 3 } & $1 \mathrm{e} 14$ & -600 \\
\hline \multirow{3}{*}{$-5 \mathrm{e} 12$} & $1 \mathrm{e} 13$ & -70 \\
\cline { 2 - 3 } & $5 \mathrm{e} 13$ & -100 \\
\cline { 2 - 3 } & $1 \mathrm{e} 14$ & -190 \\
\hline
\end{tabular}

\section{Summary}

The effects of fixed charges and interface charges in the JTE zones on the breakdown voltage of $\mathrm{SiC}$ power BJTs are thoroughly investigated by employing the TCAD simulation. We have shown that the influence of the fixed charges on the breakdown voltage plays a larger role than the interface traps. The fixed charges modify the effective dose of the JTEs, and change the location of the maximum electric field towards the base edge. It results in higher leakage current and lower breakdown voltage. The simulation results also show that the positive fixed charges reduce the breakdown voltage more than the negative fixed charges. By having a combination of interface traps and fixed charges simultaneously, it is possible to optimize the breakdown voltage. A higher density of interface traps will improve the $\mathrm{V}_{\mathrm{BR}}$ if fixed charges are present.

\section{References}

[1] M. Ostling, in:, IEEE Electron Devices Meet., San Francisco, CA, 2010, pp. 13.3.1 - 13.3.4.

[2] B.J. Baliga, Fundamentals of Power Semiconductor Devices, Springer, New York, 2008.

[3] J. Zhang, X. Li, P. Alexandrov, J.H. Zhao, Electron Device Lett. IEEE 29 (2008) 471. 
[4] R. Ghandi, M. Domeij, B. Buono, C.-M. Zetterling, M. Östling, IEEE Electron Device Lett. 29 (2008) 1135.

[5] B. Buono, H.S. Lee, M. Domeij, C.M. Zetterling, M. Östling, Mater. Sci. Forum 615-617 (2009) 841.

[6] R. Ghandi, B. Buono, M. Domeij, R. Esteve, A. Schoner, J. Han, S. Dimitrijev, S.A. Reshanov, C.M. Zetterling, M. Ostling, IEEE Trans. Electron Devices 58 (2011) 259.

[7] V. V Afanasev, M. Bassler, G. Pensl, M. Schulz, Phys. Stat. Sol. 162 (1997) 321.

[8] R. Singh, Microelectron. Reliab. 46 (2006) 713.

[9] P. Jamet, S. Dimitrijev, P. Tanner, J. Appl. Phys. 90 (2001) 5058.

[10] L. Lanni, Silicon Carbide Bipolar Technology for High Temperature Integrated Circuits Doctoral Thesis in Information and Communication Technology, KTH Royal Institute of Technology, Stockholm, 2014.

[11] H.-S. Lee, M. Domeij, C.-M. Zetterling, M. Östling, F. Allerstam, E.O. Sveinbjörnsson, Appl. Phys. Lett. 92 (2008) 082113.

[12] H.-S. Lee, M. Domeij, C.-M. Zetterling, M. Östling, F. Allerstam, E.Ö. Sveinbjörnsson, Appl. Phys. Lett. 92 (2008).

[13] A. Salemi, H. Elahipanah, B. Buono, C.M. Zetterling, M. Östling, Mater. Sci. Forum 740-742 (2013) 974.

[14] Sentaurus TCAD, Synopsis Inc. Version D-2010.03, March 2010, Synopsis Inc., n.d. 